\title{
Effect of oxygen limitation on the enrichment of bacteria degrading either benzene or toluene and the identification of Malikia spinosa (Comamonadaceae) as prominent aerobic benzene-, toluene-, and ethylbenzene-degrading bacterium: enrichment, isolation and whole-genome analysis
}

\author{
Fruzsina Révész $^{1,2} \cdot$ Milán Farkas $^{1,2} \cdot$ Balázs Kriszt $^{1,2} \cdot$ Sándor Szoboszlay ${ }^{2} \cdot$ Tibor Benedek $^{1,2} \cdot$ András Táncsics $^{1,2}$ (I)
}

Received: 3 March 2020 / Accepted: 12 May 2020 / Published online: 30 May 2020

(C) The Author(s) 2020

\begin{abstract}
The primary aims of this present study were to evaluate the effect of oxygen limitation on the bacterial community structure of enrichment cultures degrading either benzene or toluene and to clarify the role of Malikia-related bacteria in the aerobic degradation of BTEX compounds. Accordingly, parallel aerobic and microaerobic enrichment cultures were set up and the bacterial communities were investigated through cultivation and 16S rDNA Illumina amplicon sequencing. In the aerobic benzene-degrading enrichment cultures, the overwhelming dominance of Malikia spinosa was observed and it was abundant in the aerobic toluene-degrading enrichment cultures as well. Successful isolation of a Malikia spinosa strain shed light on the fact that this bacterium harbours a catechol 2,3-dioxygenase (C23O) gene encoding a subfamily I.2.C-type extradiol dioxygenase and it is able to degrade benzene, toluene and ethylbenzene under clear aerobic conditions. While quick degradation of the aromatic substrates was observable in the case of the aerobic enrichments, no significant benzene degradation, and the slow degradation of toluene was observed in the microaerobic enrichments. Despite harbouring a subfamily I.2.C-type C23O gene, Malikia spinosa was not found in the microaerobic enrichments; instead, members of the Pseudomonas veronii/extremaustralis lineage dominated these communities. Whole-genome analysis of $M$. spinosa strain $\mathrm{AB} 6$ revealed that the $\mathrm{C} 23 \mathrm{O}$ gene was part of a phenol-degrading gene cluster, which was acquired by the strain through a horizontal gene transfer event. Results of the present study revealed that bacteria, which encode subfamily I.2.C-type extradiol dioxygenase enzyme, will not be automatically able to degrade monoaromatic hydrocarbons under microaerobic conditions.
\end{abstract}

Keywords Malikia spinosa $\cdot$ BTEX degradation · Bioremediation $\cdot$ Petroleum hydrocarbons $\cdot$ Groundwater

\section{Introduction}

Responsible Editor: Robert Duran

Electronic supplementary material The online version of this article (https://doi.org/10.1007/s11356-020-09277-z) contains supplementary material, which is available to authorized users.

András Táncsics

tancsics.andras@ fh.szie.hu

1 Regional University Center of Excellence in Environmental Industry, Szent István University, Gödöllő, Hungary

2 Department of Environmental Protection and Safety, Szent István University, Gödöllő, Hungary
Monoaromatic pollutants such as benzene, toluene, ethylbenzene and isomers of xylene (BTEX compounds) are volatile organic hydrocarbons. BTEX compounds are produced and used during the processing of petroleum products and widely used in industry, e.g. in the manufacture of paints, varnishes, insecticides, pharmaceuticals and solvents. Besides extraction, usage, storage and transport, accidentally they are often released into the environment, causing a serious threat to soil and groundwater ecosystems. They are relatively soluble in water, therefore tended to spread quickly in the direction of groundwater movement. Each BTEX compound can cause neurological disturbances; in addition, benzene can cause 
hematological effects including aplastic anemia and acute myelogenous leukemia in humans (Fenga et al. 2016).

In bioremediation procedures, bacteria are used to eliminate xenobiotics. Some microorganisms are able to use a wide range of petroleum derivatives as a source of carbon and energy for their metabolic processes. It is well known that aromatic hydrocarbons, such as the BTEX compounds, decompose most rapidly and completely under aerobic conditions (El-Naas et al. 2014). Aerobic BTEX degraders use mono- and dioxygenases for the hydroxylation and the subsequent cleavage of the aromatic ring. Consequently, these enzymes require molecular oxygen as a co-substrate. However, in polluted subsurface environments, the availability of dissolved oxygen is often limited. In these environments, a specific group of extradiol dioxygenases (subfamily I.2.C), adapted to low oxygen concentrations (Kukor and Olsen 1996), can have a key role in the catalysis of the ring cleavage reaction. Recently, evidence was found for the ring-cleavage activity of this I.2.C-type extradiol

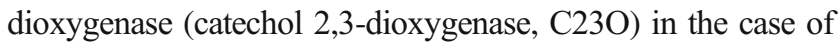
Zoogloea oleivorans degrading toluene under microaerobic conditions (Táncsics et al. 2020). On the other hand, not all of the I.2.C $\mathrm{C} 23 \mathrm{O}$ genotypes can be linked to the ability of microaerobic BTEX degradation, as it was shown in our previous enrichment study (Benedek et al. 2018). We have revealed that different subfamily I.2.C-type $\mathrm{C} 23 \mathrm{O}$ genes and different members of the Betaproteobacteriales were dominant under aerobic versus microaerobic conditions in BTEXdegrading enrichment cultures (Benedek et al. 2018). In the aerobic BTEX-degrading enrichments, members of the genus Malikia were dominant, while members of the genus Acidovorax were the most abundant under microaerobic conditions. Unfortunately, isolation of representatives of these dominant genera was not succeeded; therefore, the dominant subfamily I.2.C-type $\mathrm{C} 23 \mathrm{O}$ genotypes were linked to them only theoretically (Benedek et al. 2018).

The main aim of the present study was to re-enrich and isolate Malikia-related bacteria, to confirm our presumption that they can harbour subfamily I.2.C-type C23O gene, and that they can play role in the degradation of certain BTEX compounds, but solely under clear aerobic conditions. For this, aerobic and microaerobic enrichment cultures were set up by using biofilm material originated from the same site as in the case of our previous enrichment (Benedek et al. 2018).

\section{Materials and methods}

\section{Enrichment setup and process measurements}

To reach the goals of the present study, aerobic and microaerobic enrichments were set up in triplicate. For the inoculation of the microcosms, biofilm sample was obtained from a petroleum hydrocarbon-contaminated site, located in central Hungary. Previous studies have shown the diverse occurrence of hydrocarbon-degrading bacteria in this biofilm material (Benedek et al. 2016, 2018). To assemble the enrichment microcosms, 100-mL serum bottles were used, sealed with butyl-rubber septa and aluminium crimp seals. Fifty milliliters of mineral salt (MS) medium (Fahy et al. 2006) was used for each enrichment culture supplemented with vitamins $\left(1 \mathrm{mg} / \mathrm{L}\right.$ thiamine, $15 \mu \mathrm{g} / \mathrm{L}$ biotin and $20 \mu \mathrm{g} / \mathrm{L}$ vitamin $\mathrm{B}_{12}$ ), and then amended with benzene or toluene as sole carbon and energy source at a concentration of $1 \mathrm{mM}$.

Before inoculation of the microaerobic enrichments, microcosms were sparged with $\mathrm{N}_{2} / \mathrm{CO}_{2}(80: 20$, v/v) for $10 \mathrm{~min}$. The desired concentration of dissolved oxygen was then adjusted by injection of sterile air $(0.2 \mu \mathrm{m}$ pore size filtered) through the butyl-rubber septa. Initial enrichment cultures were inoculated with $1 \mathrm{~g}$ (wet weight) of biofilm sample. Changes in dissolved oxygen concentration in the bottles were monitored noninvasively by Fibox 3 trace v3 fibre optic oxygen meter with PSt3 sensor spots (PreSens). To maintain aerobic and microaerobic conditions, oxygen was continuously replenished in the enrichments. Microcosms were incubated in a shaking thermostat $\left(28^{\circ} \mathrm{C}, 150 \mathrm{rpm}\right)$ for 1 week, and then $5 \mathrm{~mL}$ of each enrichment was inoculated into fresh MS medium. The transfers were carried out for five consecutive weeks.

Concentrations of benzene and toluene were determined in the case of the 5th week enrichments in every $24 \mathrm{~h}$ by headspace analysis on an ISQ Single Quadrupole gas chromatography-mass spectrometer (GC-MS) (Thermo Fischer Scientific) via a SLB-5ms fused silica capillary column (Supelco Analytical). The oven temperature was set to $40{ }^{\circ} \mathrm{C}$ for $3 \mathrm{~min}$, then ramped at a rate of $20^{\circ} \mathrm{C} \mathrm{min}^{-1}$ to $190^{\circ} \mathrm{C}$, and held for $1 \mathrm{~min}$. The mass spectrometer was operated at $250^{\circ} \mathrm{C}$ in full scan mode. Triplicates of uninoculated bottles with 50 $\mathrm{mL}$ of MS medium containing either $1 \mathrm{mM}$ benzene or toluene served as negative controls for the GC-MS measurements.

\section{DNA isolation and T-RFLP fingerprinting}

After five consecutive transfers, the microbial biomass was harvested from $50 \mathrm{~mL}$ enrichments by centrifugation at $2360 \mathrm{~g}$ at $4{ }^{\circ} \mathrm{C}$ for $10 \mathrm{~min}$ using a Rotanta $460 \mathrm{R}$ (Hettich) and DNA was isolated from the pellets by using the DNeasy UltraClean Microbial Kit (Qiagen) according to the instructions of the manufacturer. To isolate DNA from the biofilm inoculum, the NucleoSpin Soil Kit (Macherey-Nagel) was used by following the instructions of the manufacturer. For 16S rDNA-based T-RFLP community fingerprinting, the VIC-labelled PCR amplicons were generated by using $27 \mathrm{f}-$ VIC (5'-AGA GTT TGA TCM TGG CTC AG-3') and 1492r primers (5'-TACGGYTACCTTGTTACGACTT-3') as described earlier (Benedek et al. 2016). The PCR reaction mixture (final volume of $50 \mu \mathrm{L}$ ) included: $5 \mu \mathrm{L}$ of $10 \mathrm{x}$ DreamTaq Buffer (Thermo Fischer Scientific), $0.2 \mathrm{mM}$ of 
each of the four dNTP, $0.3 \mu \mathrm{M}$ of each primer, $0.25 \mu \mathrm{L}$ of a 5 $\mathrm{U} \mu \mathrm{L}^{-1}$ DreamTaq DNA Polymerase solution (Thermo Fisher Scientific), $20 \mathrm{ng}$ template DNA and autoclaved MilliQ water up to $50 \mu \mathrm{L}$. All amplifications were performed in a ProFlex PCR System (Life Technologies). All amplification products were checked by electrophoresis on $1 \%$ agarose gels stained with ethidium bromide.

The obtained VIC-labelled 16S rDNA PCR products were digested with $1 \mathrm{U} R s a \mathrm{I}(\mathrm{GT} \downarrow \mathrm{AC}$ ) restriction enzyme (Thermo Fischer Scientific) for $1.5 \mathrm{~h}$ at $37^{\circ} \mathrm{C}$. The generated fluorescently labelled terminal restriction fragments (T-RFs) were purified by ethanol precipitation method. After ethanol precipitation, fragments were separated on a Model 3130 Genetic Analyzer (Applied Biosystems), while primary evaluation of electropherograms was performed using GeneMapper 4.0 software (Applied Biosystems). T-RFLP data were handled as described earlier (Farkas et al. 2017). Cluster analysis (Bray-Curtis method) of the T-RFLP electropherograms was performed by using the PAST 3.26 software package (Hammer et al. 2001).

\section{S rDNA amplicon sequencing and data handling}

$16 \mathrm{~S}$ rDNA amplicon sequencing was carried out from the initial biofilm sample as well as from one representative of the triplicate fifth week enrichment cultures. The variable V3 and V4 regions of the $16 \mathrm{~S}$ rRNA gene were amplified by using the PCR primers suggested by Klindworth et al. (2013). KAPA HiFi HotStart Ready Mix-et (KAPA Biosystems) was used for PCR according to the $16 \mathrm{~S}$ metagenomics sequencing library preparation guide of Illumina. Paired-end fragment reads were generated on an Illumina MiSeq sequencer using MiSeq Reagent Kit v3 (600-cycle) by SeqOmics Biotechnology Ltd. (Mórahalom, Hungary). Read numbers were the following: 33,778 for enrichment AB1; 29,721 for enrichment AT2,; 33,056 for enrichment MB1; 36,823 for enrichment MT3 and 33,820 for initial biofilm sample (BUT18). Primary data analysis (base calling) was carried out with Bbcl2 fastq ${ }^{\wedge}$ software (v2.17.1.14, Illumina). Reads were quality and length trimmed in CLC Genomics Workbench Tool 9.5.1 using an error probability of $0.05(\mathrm{Q} 13)$ and a minimum length of 50 nucleotides as a threshold. Trimmed sequences were processed using mothur v1.41.1 (Schloss et al. 2009) as recommended by the MiSeq SOP page (http://www.mothur.org/ wiki/MiSeq SOP) (Kozich et al. 2013). Sequences were assorted based on the alignment using SILVA 132 SSURef NR99 database (Quast et al. 2013). Chimera detection was carried out with mothur's uchime command (Edgar et al. 2011), and 'split.abund' command was also used to remove singleton reads according to Kunin et al. (2010). Taxonomic assignments were made against SILVA release 123 applying a minimum bootstrap confidence score of $80 \%$. Operational taxonomic units (OTUs) were assigned at 97\% similarity threshold level as suggested by Tindall et al. (2010) for prokaryotic species delineation. Sequence reads were deposited in NCBI SRA under BioProject ID PRJNA433949 (Inoculum: SRX7512837, aerobic benzene-degrading enrichment culture AB1: SRX7512838, aerobic toluene-degrading enrichment culture AT2: SRX7512839, microaerobic benzene-degrading enrichment culture MB1: SRX7512840 and microaerobic toluene-degrading enrichment culture MT3: SRX7512841).

\section{Cloning of I.2.C C230 amplicons, Sanger-sequencing and phylogenetic analysis}

Subfamily I.2.C-type $C 23 O$ genes were PCR amplified by using the primers XYLE3f (5'-TGY TGG GAY GAR TGG GAY AA-3') and XYLE3r (5'-TCA SGT RTA SAC ITC SGT RAA-3') and were cloned and sequenced as described earlier (Táncsics et al. 2012; Táncsics et al. 2013). The C23O sequences of each clone library were manually grouped into operational protein units (OPUs) by applying a cutoff value of 0.03. Terminal restriction fragments (T-RFs) predicted in silico for representative clones of each of the OPUs were verified in vitro. The neighbour-joining phylogenetic tree was reconstructed based on the deduced amino-acid sequences by using MEGA ver. 7.0 (Kumar et al. 2016). For tree reconstruction the Jones-Taylor-Thornton model was used and gaps were treated by complete deletion; the number of bootstrap replications was set to 1000 , while the substitution rates were set to be the same among the sites and lineages. Representative clones of each OPU were deposited with GenBank and can be found under the accession numbers MN823973-MN823982.

\section{Isolation and identification of bacterial strains from the enrichments}

To gain bacterial isolates from the enrichments, serially diluted samples were spread on the surface of R2A agar plates (proteose peptone $0.5 \mathrm{~g}$, casamino acids $0.5 \mathrm{~g}$, yeast extract $0.5 \mathrm{~g}$, dextrose $0.5 \mathrm{~g}$, soluble starch $0.5 \mathrm{~g}$, dipotassium phosphate $0.3 \mathrm{~g}$, MgSO $47 \mathrm{H}_{2} \mathrm{O} 0.05 \mathrm{~g}$, sodium pyruvate $0.3 \mathrm{~g}$, agar $15 \mathrm{~g}$, pH $7 \pm 0.2$ ). Chemicals were obtained from SigmaAldrich, Germany. After 1 week of incubation $\left(28^{\circ} \mathrm{C}\right)$, colonies with different morphologies were purified by streak plating technique and maintained on R2A agar slants at $28^{\circ} \mathrm{C}$. DNA isolation from the isolates was performed by using the UltraClean Microbial DNA Kit (Qiagen) according to the instructions of the manufacturer. The 16S rRNA genes of the isolates were amplified by using the bacterial PCR primers $27 \mathrm{f}$ and 1492r, while XYLE3f/XYLE3r primer set was used to amplify the subfamily I.2.C-type C23O genes as described above. Sequencing of the 16S rDNA and C23O amplicons was performed according to Benedek et al. (2018). The 16S 
rRNA and $\mathrm{C} 23 \mathrm{O}$ gene sequences of the isolates were deposited with GenBank under the accession numbers MN449442MN449463 and MN481621-MN481623, respectively. Transmission electron microscopic observations were performed by applying negative staining (Szoboszlay et al. 2008) and the shadow-casting technique (Ohad et al. 1963), respectively.

\section{BTEX-degradation analysis of the isolates}

The ability of the isolates to degrade individual BTEX compounds under aerobic conditions was investigated by GC-MS analysis. Measurements were carried out in triplicates of 100 $\mathrm{mL}$ crimped serum bottles containing $50 \mathrm{~mL}$ of MS medium, amended with an individual BTEX compound at a concentration of $5 \mathrm{mg} / \mathrm{L}$. Enrichments were inoculated with $100 \mu \mathrm{L}$ bacterial suspensions (OD600 0.5) and incubated in a rotary shaker at $28^{\circ} \mathrm{C}$ and $150 \mathrm{rpm}$. Uninoculated bottles served as negative controls. Concentrations of BTEX compounds were determined in every 24 -h interval by headspace GC-MS analysis as detailed above.

\section{Whole-genome sequencing and comparative genomics analysis}

Whole-genome sequencing was performed as described previously by SeqOmics Biotechnology Ltd. (Mórahalom, Hungary) (Borsodi et al. 2019), briefly: Nextera Mate Pair Sample Preparation Kit (Illumina) was used to generate mate-paired libraries according to the manufacturer's protocol for gel-plus version with slight modifications. Thirteen microliters of Mate Pair Tagment Enzyme was used to produce a robust smear within the 7-11 kbp region. The 7-11 kbp DNA fraction was excised from the gel using the Zymoclean Large Fragment DNA Recovery kit (Zymo Research), and the circularized DNA was sheared using Covaris S2. All quality measurements were performed on a TapeStation 2200 instrument (Agilent). Final libraries were quantified using Qubit (ThermoFisherScientific) and sequenced on an Illumina MiSeq instrument using MiSeq Reagent Kit v2 (500 cycles) sequencing chemistry. De novo assembly and scaffolding was performed with CLC Genomics Workbench Tool v11 (Qiagen). Automatic annotation of the genome was performed by the NCBI Prokaryotic Genomes Automatic Annotation Pipeline (PGAP) v4.5 (Tatusova et al. 2016). Annotation was also performed by using the RAST server (through the RASTtk scheme) and the SEED database (Aziz et al. 2008; Overbeek et al. 2014; Brettin et al. 2015). Graphical visualization of gene clusters was performed by using SnapGene v4.3.4. To perform digital DNA-DNA hybridization analysis, the online available genome-to-genome distance calculator (GGDC, version 2.1) was used (Meier-Kolthoff et al. 2013). To calculate orthologous average nucleotide identity value
(OrthoANI), the OAT software was used (Lee et al. 2016). OrthoVenn2 software (Xu et al. 2019) was used to perform comparative genomics analysis.

\section{Results and discussion}

\section{Microbial community compositions as revealed by $16 \mathrm{~S}$ rDNA amplicon sequencing}

For the inoculation of the enrichment cultures, a biofilm material was used, which was taken from a groundwater well of an extensively studied Hungarian petroleum hydrocarboncontaminated site (Benedek et al. 2016). The sampled biofilm continuously developed on the stainless steel surface of a submersible pump, which was part of a pump-and-treat system operating at the contaminated site. In previous enrichment studies, this continuously emerging biofilm was successfully used to study the biodegradation of petroleum hydrocarbons under microaerobic conditions (Benedek et al. 2018; Révész et al. 2020). Members of the class Gammaproteobacteria overwhelmingly dominated the bacterial community of the newly sampled biofilm material (47\% of $16 \mathrm{~S}$ rDNA sequence reads) (Online Resource 1, Fig. S1). Moreover, mainly genera of the Betaproteobacteriales were abundant, such as members of the Sulfuritaela (9.7\%), Azoarcus (6.5\%), Zoogloea (4.7\%), Simplicispira (3\%), Thauera (2.4\%), Denitratisoma (1\%), Leptothrix (0.9\%), Acidovorax (0.8\%) and Malikia (0.7\%). Many of these genera contain well-known aromatic hydrocarbon degraders (e.g. Azoarcus, Zoogloea, Thauera and Acidovorax) (Prince et al. 2018), or frequently found in petroleum hydrocarbon-contaminated subsurface environments (e.g. Sulfuritalea, Simplicispira and Denitratisoma) (Sperfeld et al. 2018). Due to this enormous diversity of potentially petroleum hydrocarbon-degrading bacteria, the biofilm material was an excellent inoculum for the benzene- and toluene-degrading enrichments. Most importantly, Malikiarelated bacteria were detectable in this biofilm community.

By using the biofilm inoculum, aerobic $(7-8 \mathrm{mg} / \mathrm{L}$ dissolved oxygen $)$ and microaerobic enrichments $(0.5 \mathrm{mg} / \mathrm{L}$ dissolved oxygen) were set up in triplicates with either benzene or toluene as a sole source of carbon and energy. Enrichments were then transferred weekly for consecutive 5 weeks. At the fifth week, aromatic hydrocarbon degradation processes in the enrichments reflected that highly efficient degrading communities evolved in the aerobic benzene- and toluene-degrading enrichments, respectively. In these enrichments, the carbon source was almost depleted by the third day of incubation, and no aromatic hydrocarbon was detectable by the seventh day (Fig. $1 \mathrm{a}$ and b). On the other hand, under microaerobic conditions, the level of aromatic hydrocarbon degradation was significantly lower. Notable degradation was observable only in the toluene-containing enrichments, in which $\sim 40 \%$ of 
Fig. 1 Degradation process of aromatic hydrocarbons in the aerobic enrichments containing a benzene, or $\mathbf{b}$ toluene and in the microaerobic enrichments containing $\mathbf{c}$ benzene, or $\mathbf{d}$ toluene. Benzene and toluene concentrations were measured by GC-MS analysis at the 5th week of enrichment as described in the main text. Means of triplicate enrichments are given (with standard error)
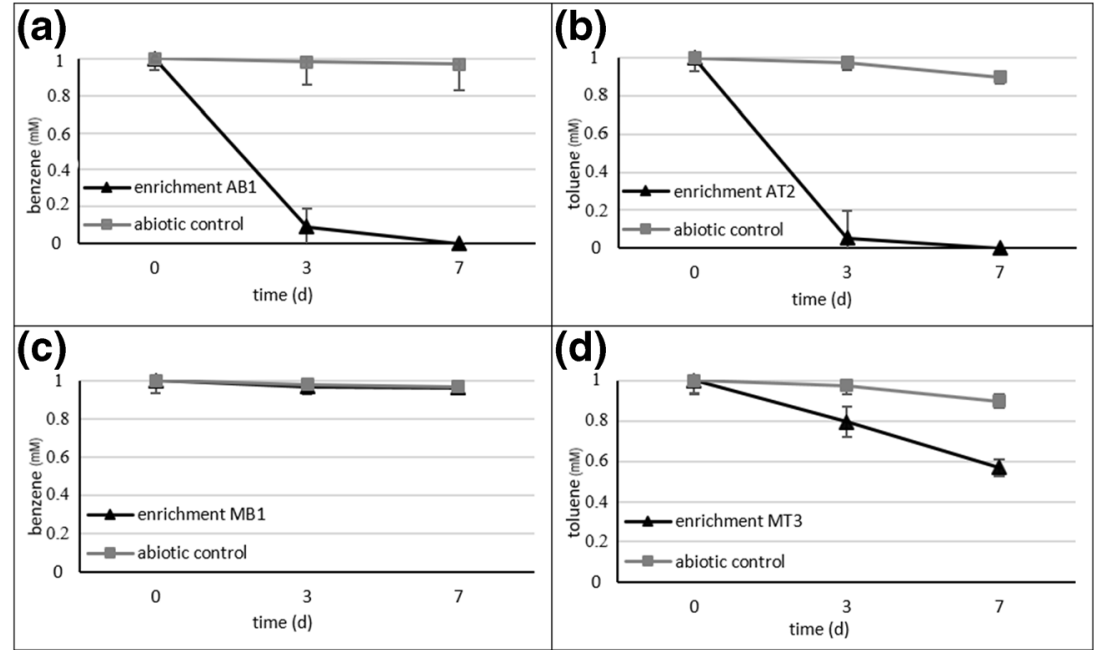

toluene was degraded by the seventh day of incubation (Fig. 1d), while in the benzene-containing enrichments no significant degradation was observed (Fig. 1c). After the fifth week of enrichment, the bacterial community compositions were first investigated by using $16 \mathrm{~S}$ rDNA-based T-RFLP. The Bray-Curtis similarity-based dendrogram of the T-RFLP profiles showed that the bacterial communities of the aerobic and microaerobic enrichments were entirely different (Online Resource 1, Fig. S2). The aerobic enrichments degrading either benzene or toluene belonged to one clear group of the dendrogram, but it was also observable that different subgroups of the dendrogram contained the benzene- and the toluene-degrading enrichments. On the other hand, the microaerobic enrichments separated into two distinct groups, depending on the type of aromatic hydrocarbon (i.e. benzene or toluene). Furthermore, it was also noticeable that the triplicate enrichments had mostly similar community compositions. Accordingly, one representative of each triplicate enrichment was chosen for detailed community analysis.

The bacterial community of the aerobic benzene-degrading enrichment ( $\mathrm{BB} 1$ ) was dominated by a single genus, since more than $94 \%$ of $16 \mathrm{~S}$ rDNA sequence reads could be linked to the genus Malikia (Betaproteobacteriales, Comamonadaceae) (Fig. 2a). Besides, members of the genera Pseudomonas, Acidovorax and Flavobacterium were detectable with notable abundance $(>0.5 \%)$. At the time of writing, the genus Malikia contained two species. The type species of the genus is $M$. granosa, which was described as a polyhydroxyalkanoate- and polyphosphate-accumulating bacterium, isolated from wastewater activated sludge (Spring et al. 2005). The other member of the genus was isolated from river water and described as Pseudomonas spinosa (Leifson 1962), and later reclassified as $M$. spinosa by Spring et al. (2005). Although the occurrence of the genus Malikia in BTEXcontaminated subsurface environments has already been reported by some studies (Aburto and Ball 2009; Táncsics et al. 2010) though their exact role remained hidden. The closest relatives of Malikia species can be found in the genus Hydrogenophaga, which contains excellent BTEX degraders (Fahy et al. 2008; Jechalke et al. 2013). Nevertheless, Malikia isolates with aromatic hydrocarbon-degrading ability have not been reported yet in the literature. Our previous enrichment study enabled to speculate that these bacteria could be active aromatic hydrocarbon degraders (Benedek et al. 2018).

The bacterial community of the aerobic toluene-degrading enrichment (AT2) was dominated by members of the genus Pseudomonas (66\%), followed by Malikia (18.9\%), Flavobacterium (10.2\%) and Acidovorax (1.5\%) (Fig. 2b). The dominant role of Pseudomonas-related bacteria in toluene degradation under fully aerobic conditions is well known. Consequently, these bacteria are widely investigated as model organisms for the study of aerobic toluene degradation. The high abundance of sequence reads affiliated with the genus Malikia enabled to assume that these bacteria also played role in the aerobic degradation of toluene. This ability has never been linked before to these bacteria. On the other hand, members of the genera Flavobacterium and Acidovorax are frequently observed in petroleum hydrocarbon-contaminated environments (Kaplan and Kitts 2004; Aburto et al. 2009; Singleton et al. 2018).

The bacterial community of the microaerobic, benzenecontaining enrichment (MB1) was considerably simple, since all of the $16 \mathrm{~S}$ rDNA sequence reads could be affiliated with the genus Pseudomonas (Fig. 2c). Nevertheless, no significant benzene degradation was observed in this enrichment culture. It is highly assumable that these Pseudomonas bacteria were feeding on cell debris or secondary metabolites of other bacteria, which were present in the enrichment only in trace amounts. Contrarily, the bacterial community of the microaerobic, toluene-degrading enrichment (MT3) had a bit larger diversity (Fig. 2d). Although still members of the genus Pseudomonas dominated the community (81\%), members of the genera Simplicispira (9.1\%), Herminiimonas (4.9\%) and 
Fig. 2 Genus level bacterial community structure of enrichments AB1, AT2, MB1 and MT3 as revealed by Illumina paired-end 16S rDNA amplicon sequencing. All taxa contributing more than $0.5 \%$ abundance were depicted
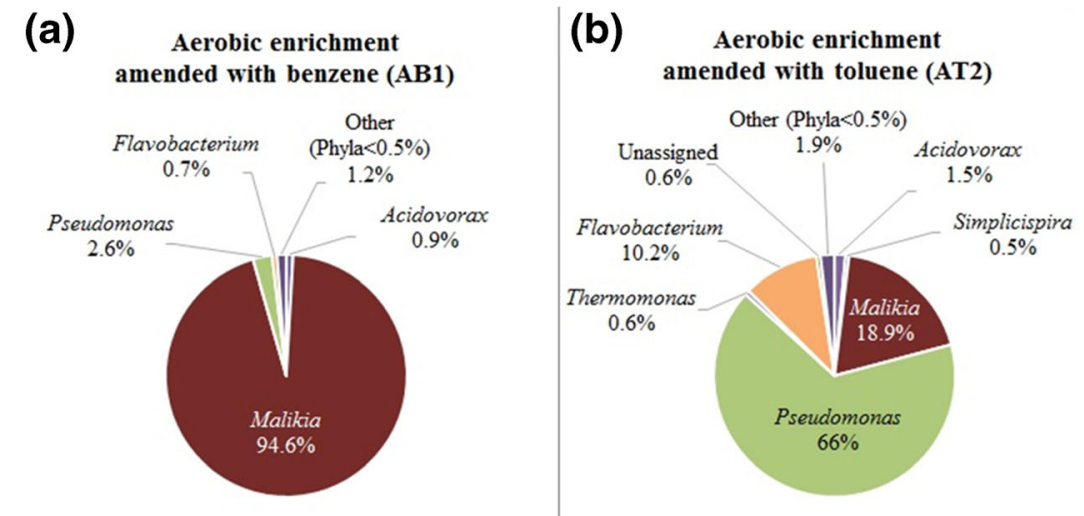

(c) $\begin{gathered}\text { Microaerobic enrichment } \\ \text { amended with benzene (MB1) }\end{gathered}$

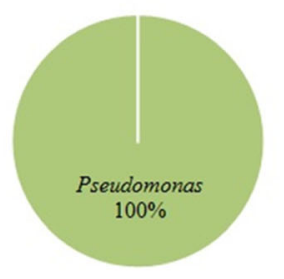

Acidovorax (3.3\%) were also detected with notable abundance. Members of the genus Herminiimonas probably took part in the degradation of toluene during periods when oxygen was depleted from the enrichments and anaerobic conditions prevailed. This can be assumed based on the study of Kim et al. (2014) which reported on an uncultivated Herminiimonas-related bacterium capable of degrading toluene under nitrate-reducing conditions. The metagenomeassembled genome of this bacterium contained genes encoding the benzylsuccinate synthase, which is the key enzyme of anaerobic toluene degradation and known to be highly oxygen sensitive (Leuthner et al. 1998). Members of genera Simplicispira and Acidovorax are frequently observed in oxygen-limited, petroleum hydrocarbon-degrading enrichment cultures (Keller et al. 2018; Révész et al. 2020); therefore, their role in the degradation can be also assumed.

\section{Diversity and phylogenetic affiliation of subfamily I.2.C-type C230 gene clones}

In the case of those enrichments, which were analysed by Illumina 16S rDNA amplicon sequencing, the diversity of subfamily I.2.C-type $\mathrm{C} 23 \mathrm{O}$ genes was also recovered. In the aerobic benzene-degrading enrichment culture (AB1), all of the subfamily I.2.C-type $\mathrm{C} 23 \mathrm{O}$ gene sequences belonged to a single OPU (AB_OPU-1). Moreover, this C23O genotype was identical with that of was found earlier by us in the case of an aerobic BTEX-degrading enrichment culture (Fig. 3) and was putatively linked to the genus Malikia (Benedek et al. 2018). Surprisingly, this was the only detectable subfamily I.2.C-type $\mathrm{C} 23 \mathrm{O}$ genotype in the aerobic toluenedegrading enrichment culture (AT2) as well (AT_OPU-1). Although no significant benzene degradation was found in the microaerobic enrichments, the largest $\mathrm{C} 23 \mathrm{O}$ diversity was detectable in the case of enrichment MB1, since the $\mathrm{C} 23 \mathrm{O}$ sequences could be grouped into five OPUs. This observation is in contradiction with the considerably low bacterial diversity that we have recovered in the case of this enrichment. However, this result suggests that beside Pseudomonasrelated bacteria, members of other genera were also present in the community of enrichment MB1, although most probably in trace amounts only. Most of the $\mathrm{C} 23 \mathrm{O}$ sequences in this enrichment belonged to MB_OPU-1 (69\% of clone sequences), which was most closely related to a $\mathrm{C} 23 \mathrm{O}$ of an unknown bacterium. Sequences of the MB_OPU-2 and MB_OPU-4 were most closely related to a $\mathrm{C} 23 \mathrm{O}$ sequence, which was retrieved earlier by us from a hypoxic BTEXdegrading enrichment culture (Benedek et al. 2018). Similarly, sequences of MB_OPU-3 showed high degree of similarity to a $\mathrm{C} 23 \mathrm{O}$ genotype, which was the dominant one in the aforementioned hypoxic BTEX-degrading enrichment culture. Previously, we have putatively linked this subfamily 
Fig. 3 Neighbour-joining tree showing the phylogenetic position of subfamily I.2.C-type $\mathrm{C} 23 \mathrm{O}$ amino acid sequences retrieved from enrichments and bacterial isolates. Bootstrap values from 1000 re-samplings are indicated at the branches (only values $>50 \%$ are shown). OPUs were determined using a distance cutoff of 0.03 ( $97 \%$ sequence similarity). The tree was rooted with subfamily I.2.A-type catechol 2,3-dioxygenase (xylE) amino acid sequence coded on plasmid pWW53 of Pseudomonas putida MT53

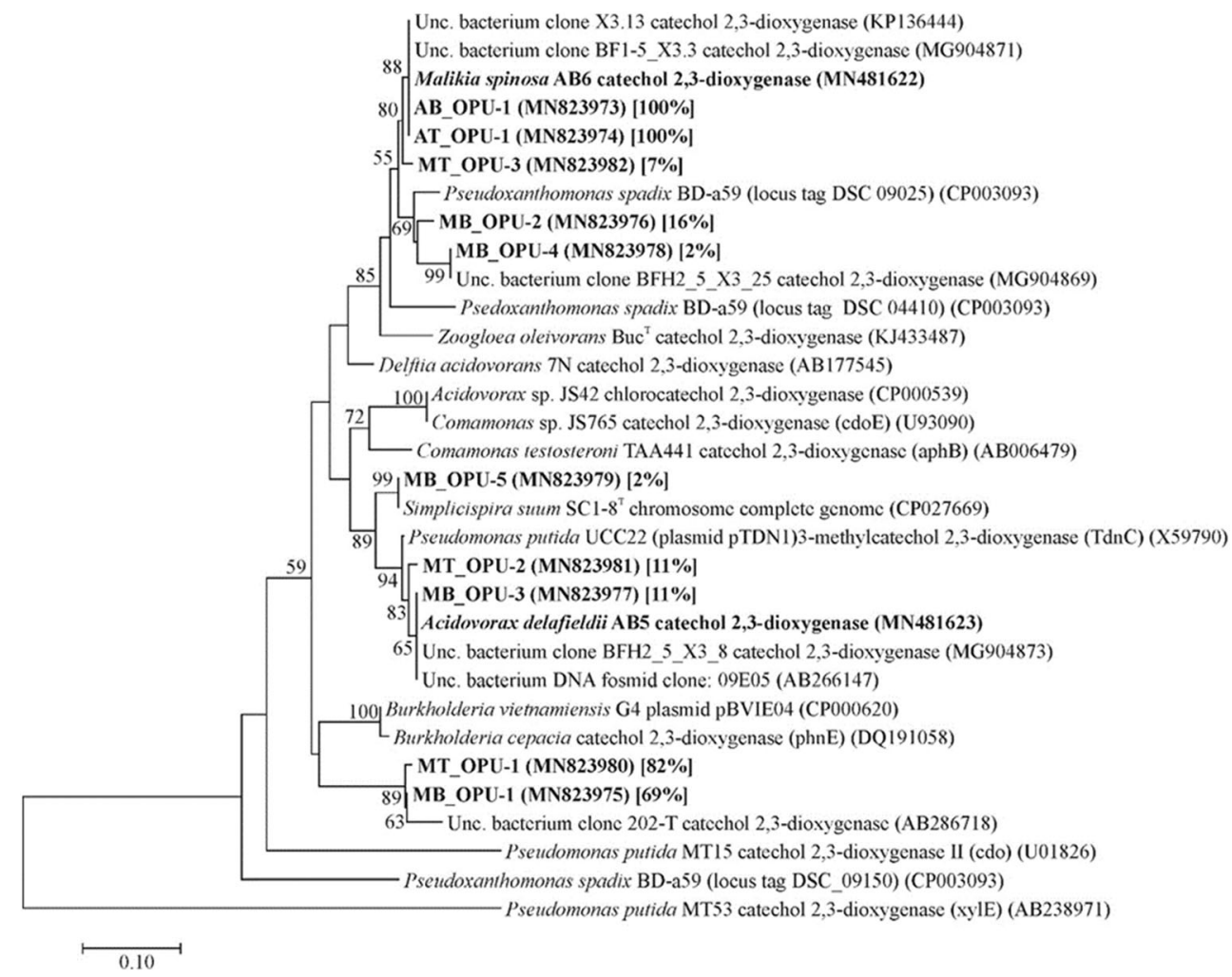

I.2.C C23O genotype to members of the genus Acidovorax (Benedek et al. 2018). Finally, the MB_OPU-5 contained a single $\mathrm{C} 23 \mathrm{O}$ sequence, which was almost identical with the C23O gene sequence of Simplicispira suum strain SC1-8. Regarding $\mathrm{C} 23 \mathrm{O}$ clone sequences of the microaerobic toluene-degrading enrichment culture MT3, they could be grouped into three OPUs. The dominant $\mathrm{C} 23 \mathrm{O}$ sequences belonged to MT_OPU-1 and were identical with sequences of MB_OPU-1 of the microaerobic enrichment MB1. Consequently, the same subfamily I.2.C-type $\mathrm{C} 23 \mathrm{O}$ genotype was dominant in both types of microaerobic enrichments. Sequences belonging to MT_OPU-2 showed high degree of similarity with sequences of MB_OPU-3, while MT_OPU-3 contained sequences, which were highly similar to sequences of OPUs of the aerobic enrichments. Overall, it can be concluded that mainly the availability of oxygen shaped the diversity of subfamily I.2.C-type $\mathrm{C} 23 \mathrm{O}$ genes in the enrichments, rather than the type of aromatic hydrocarbon (i.e. benzene versus toluene).

\section{Isolates}

Bacterial strains were isolated from those enrichments that have been analysed by Illumina $16 \mathrm{~S}$ rDNA amplicon sequencing. Not surprisingly, the diversity of the isolates was low. Altogether 22 strains were isolated, which represented only four genera (Table 1). Strains isolated from the aerobic benzene-degrading enrichment $\mathrm{AB} 1$ were members of the genera Pseudomonas, Acidovorax and Malikia. The Malikiarelated isolates were identified as Malikia spinosa strains (strains $\mathrm{AB} 2$ and $\mathrm{AB} 6$ ), showing 99.7\% 16S rDNA similarity to the type strain M. spinosa $83^{\mathrm{T}}$. Moreover, both of these strains harboured subfamily I.2.C-type $\mathrm{C} 23 \mathrm{O}$ gene. Sequence analysis of their $\mathrm{C} 23 \mathrm{O}$ amplicons revealed that these were $100 \%$ identical with the sole $\mathrm{C} 23 \mathrm{O}$ genotype found in the aerobic enrichments AB1 and AT2 (Fig. 3). For the analysis of aerobic BTEX degradation capability, the $M$. spinosa strain AB6 was chosen. As a result, it was observed that strain AB6 was able to degrade benzene, toluene and ethylbenzene (Fig. 4 ), while it was unable to degrade any isomer of xylene. According to the literature, this was the first time when a Malikia spinosa strain could be identified as an aromatic hydrocarbon-degrading bacterium. Besides, these results explained why members of the genus Malikia can be dominant bacteria of non-oxygen-limited, BTEX-contaminated environments. Transmission electron microscopic observations of strain AB6 revealed cell morphology and flagellation patterns similar to that of was reported in the case of the type strain $83^{\mathrm{T}}$ (Spring et al. 2005) (Fig. 5). Strain AB5, which was identified as Acidovorax delafieldii, also harboured subfamily I.2.C-type $\mathrm{C} 23 \mathrm{O}$ gene. This extradiol dioxygenase genotype was observed earlier by us in a microaerobic, BTEX-degrading enrichment culture (Benedek et al. 2018) (Fig. 3). The BTEXdegrading ability of strain AB5 was also investigated, and it turned out that it is able to degrade benzene only (result not shown). This ability of Acidovorax strains has already been 
Table 1 Identity of bacterial strains isolated from the enrichments

\begin{tabular}{|c|c|c|c|c|}
\hline Strain No. & Closest relative (type strain) & length of $16 \mathrm{~S}$ rDNA analysed (bp) & Similarity $(\%)$ & Subfamily I.2.C C23O gene \\
\hline \multicolumn{5}{|c|}{ Aerobic benzene-degrading enrichment culture AB1 } \\
\hline $\mathrm{AB} 1$ & Pseudomonas arsenicoxydans CECT $7543^{\mathrm{T}}$ & 1437 & 99.4 & - \\
\hline $\mathrm{AB} 2$ & Malikia spinosa ATCC $14606^{\mathrm{T}}$ & 1432 & 99.7 & + \\
\hline $\mathrm{AB} 3$ & Pseudomonas arsenicoxydans CECT $7543^{\mathrm{T}}$ & 1437 & 99.4 & - \\
\hline $\mathrm{AB} 4$ & Pseudomonas veronii DSM $11331^{\mathrm{T}}$ & 1434 & 99.8 & - \\
\hline AB5 & Acidovorax delafieldii DSM $64^{\mathrm{T}}$ & 1444 & 99.9 & + \\
\hline AB6 & Malikia spinosa ATCC $14606^{\mathrm{T}}$ & 1428 & 99.9 & + \\
\hline \multicolumn{5}{|c|}{ Aerobic toluene-degrading enrichment culture AT2 } \\
\hline AT1 & Pseudomonas umsongensis DSM $16611^{\mathrm{T}}$ & 1436 & 99.9 & - \\
\hline AT2 & Pseudomonas veronii DSM $11331^{\mathrm{T}}$ & 1435 & 99.7 & - \\
\hline AT3 & Pseudomonas moorei $\mathrm{RW} 10^{\mathrm{T}}$ & 1437 & 99.9 & - \\
\hline AT4 & Flavobacterium oncorhynchi CCUG $59446^{\mathrm{T}}$ & 1411 & 99.6 & - \\
\hline AT5 & Flavobacterium oncorhynchi CCUG $59446^{\mathrm{T}}$ & 1392 & 99.6 & - \\
\hline AT6 & Pseudomonas umsongensis DSM $16611^{\mathrm{T}}$ & 1435 & 99.9 & - \\
\hline \multicolumn{5}{|c|}{ Microaerobic benzene-containing enrichment culture MB1 } \\
\hline MB1 & Pseudomonas veronii DSM $11331^{\mathrm{T}}$ & 1437 & 99.8 & - \\
\hline MB2 & Pseudomonas veronii DSM $11331^{\mathrm{T}}$ & 1435 & 99.8 & - \\
\hline MB3 & Pseudomonas veronii DSM $11331^{\mathrm{T}}$ & 1436 & 99.8 & - \\
\hline MB4 & Pseudomonas veronii DSM $11331^{\mathrm{T}}$ & 1411 & 99.8 & - \\
\hline MB6 & Pseudomonas extremaustralis $14-3^{\mathrm{T}}$ & 1330 & 99.6 & - \\
\hline \multicolumn{5}{|c|}{ Microaerobic toluene-degrading enrichment culture MT3 } \\
\hline MT1 & Pseudomonas veronii DSM $11331^{\mathrm{T}}$ & 1438 & 99.8 & - \\
\hline MT2 & Pseudomonas veronii DSM $11331^{\mathrm{T}}$ & 1438 & 99.8 & - \\
\hline MT3 & Pseudomonas veronii DSM $11331^{\mathrm{T}}$ & 1439 & 99.8 & - \\
\hline MT4 & Pseudomonas veronii DSM $11331^{\mathrm{T}}$ & 1438 & 99.7 & - \\
\hline MT5 & Pseudomonas veronii DSM $11331^{\mathrm{T}}$ & 1451 & 99.8 & - \\
\hline
\end{tabular}

suggested in oxygen-limited, BTEX-contaminated subsurface environments by different studies (Fahy et al. 2006; Aburto and Peimbert 2011).

Strains isolated from the aerobic toluene-degrading enrichment AT2 were members of the genera Pseudomonas and Flavobacterium. Unfortunately, none of the strains harboured subfamily I.2.C-type C23O gene. Since the toluene-degrading capability of Pseudomonas strains is well known, they were not investigated further. BTEX-degrading ability of strain AT4, identified as Flavobacterium oncorhynchi, was investigated, but no such ability was observed.

All of the strains isolated from the microaerobic enrichments belonged to the Pseudomonas veronii/extremaustralis lineage. Most importantly, none of them harboured subfamily I.2.C-type C23O gene and they were unable to degrade benzene. This is in accordance with our previous result that $P$. veronii isolates enriched under microaerobic conditions from the same groundwater well were also unable to degrade benzene, and were only able to degrade toluene and $m$ - and $p$ xylene (Benedek et al. 2018). It is highly assumable that these Pseudomonas veronii/extremaustralis-related bacteria were responsible for toluene degradation in the microaerobic, toluene-degrading enrichment cultures. Although these strains did not harbour subfamily I.2.C-type C23O gene, this lineage of the genus Pseudomonas seems to be adapted to microaerobic environments. Earlier we have observed the dominance of these bacteria in microaerobic, crude oil/ gasoline mixture-degrading enrichment cultures (Benedek et al. 2018; Révész et al. 2020), and it was reported that $P$. extremaustralis preferably degrades alkanes under microaerobic conditions (Tribelli et al. 2018).

\section{Whole-genome analysis of Malikia spinosa strain AB6 in the light of its aromatic hydrocarbon-degrading ability}

The whole genome of $M$. spinosa strain AB6 was assembled into 143 contigs with 4,110,698 bps, 3868 total genes and 3614 protein coding genes (scaffold N50: 157 316; avg. coverage, 21.2; contamination, 0 ; completeness: complete). The $\mathrm{G}+\mathrm{C}$ content of the genome is $65.2 \%$. The draft genome sequence of strain AB6 has been deposited at the GenBank database under the WGS accession number VYSB00000000 (Bioproject: PRJNA572590; Biosample: SAMN12796314). 

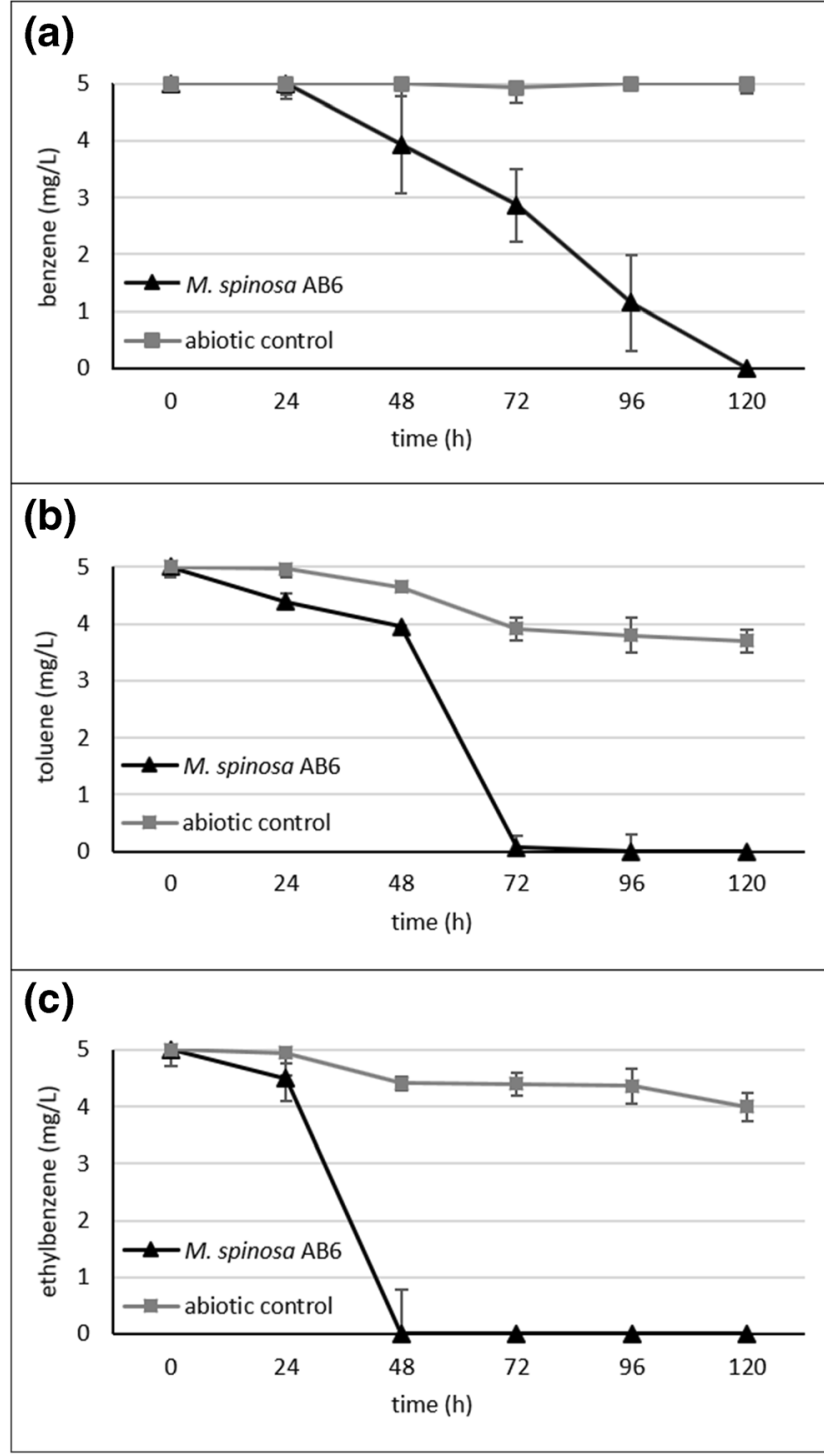

Fig. 4 Aerobic degradation of $\mathbf{a}$ benzene, $\mathbf{b}$ toluene and $\mathbf{c}$ ethylbenzene by Malikia spinosa strain AB6. Concentrations were determined by GCMS analysis as described in the main text. The averages of triplicate experiments \pm standard errors of the means, indicated by error bars, are shown

Comparing the genome sequences of strain AB6 and the type strain M. spinosa $83^{\mathrm{T}}$ (accession number PVLR00000000.1) revealed that strain AB6 has a $\sim 300 \mathrm{Kbp}$ larger genome than that of the type strain $83^{\mathrm{T}}$. Although both $\mathrm{dDDH}$ and OrthoANI analyses showed that strains $\mathrm{AB} 6$ and $83^{\mathrm{T}}$ belong to the same genomic species ( $79.4 \%$ and $97.7 \%$, respectively), pan-genomic analysis based on the OrthoVenn2 tool showed significant differences between the two genomes (Fig. 6). The analysis identified 59 clusters of proteins, containing 148 proteins, which were coded only in the genome of strain AB6 and no orthologs or paralogs of these enzymes were coded in the genome of strain $83^{\mathrm{T}}$. Moreover, a notable amount of these proteins could be linked to aromatic compound catabolic processes (data not shown). Annotation of the genome sequence
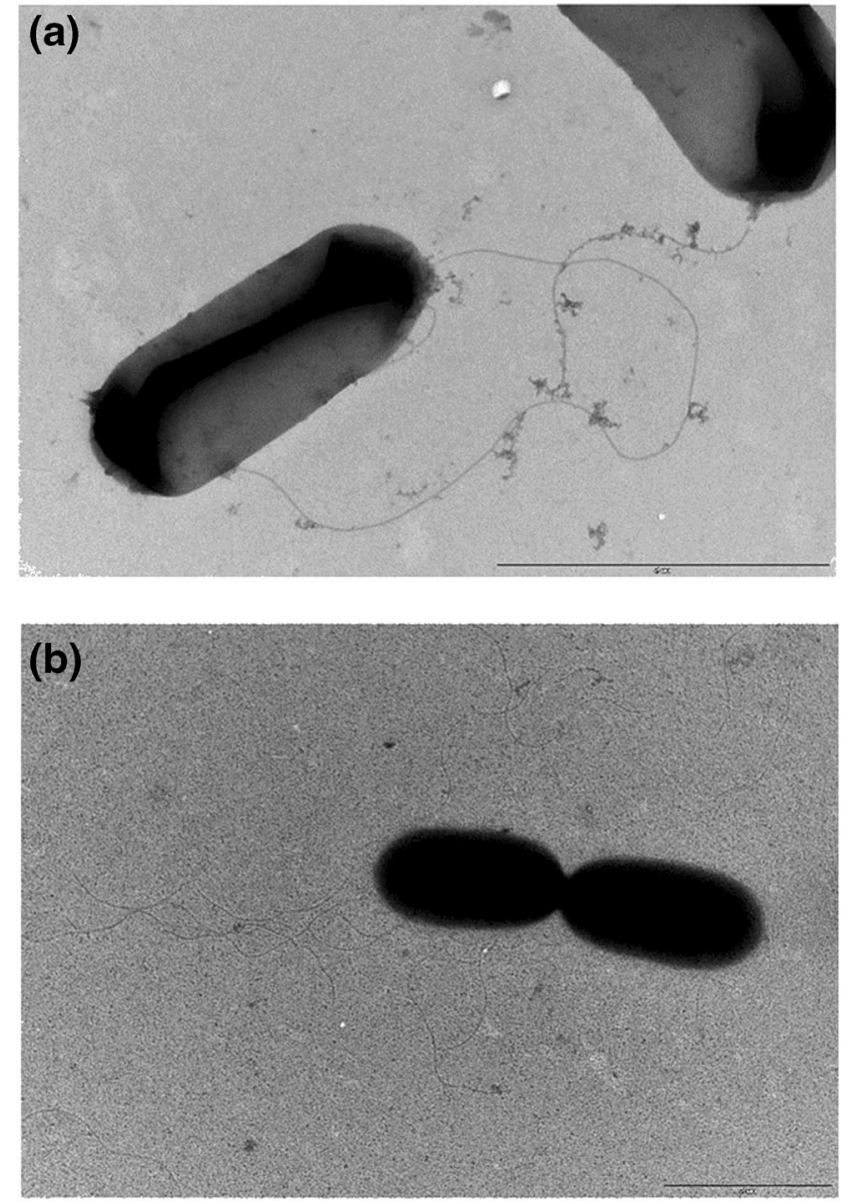

Fig. 5 Transmission electron microscopic images of Malikia spinosa strain AB6 by using a negative staining and $\mathbf{b}$ shadow-casting technique. Bar, $2 \mu \mathrm{m}$

of strain AB6 identified at least 48 genes affiliated with aromatic hydrocarbon degradation (according to SEED), while this number was only 28 in the case of strain $83^{\mathrm{T}}$.

Detailed analysis of the genome of strain AB6 revealed that the subfamily I.2.C-type $\mathrm{C} 23 \mathrm{O}$ gene was part of a phenol degradation cluster, which coded enzymes of a multicomponent phenol hydroxylase system and a complete meta-cleavage pathway (Fig. 7). Most notably, this cluster was flanked by IS5 family transposases, which fact enables us to presume that this cluster was acquired by strain AB6 through a horizontal gene transfer (HGT) event. The origin of this gene cluster cannot be exactly determined due to the fact that the proteins coded by this cluster show considerably low amino acid sequence similarities to homologous proteins coded by known bacteria (Online Resource 2 Table S1). Since no other benzene/toluene mono- and/or dioxygenase was found in the genome, it is highly assumable that this phenol-degradation cluster is responsible for both benzene- and toluene-degrading abilities of strain AB6. A similar observation was made in the case of other Comamonadaceae family-related benzene and toluene degraders, e.g. Alicycliphilus denitrificans strains BC 
Fig. 6 Comparative genomics analysis of Malikia spinosa strain AB6 and Malikia spinosa type strain $83^{\mathrm{T}}$. a Venn diagram showing the distribution of shared gene families (orthologous clusters) among the two genomes. b Totals of orthologs in each genome that were used to generate the Venn diagram. c Number of shared (2) and specific (1) orthologs. The cluster number in each component is listed (a) Malikia spinosa strain $\mathrm{AB} 6$

Malikia spinosa strain $83^{\mathrm{T}}$

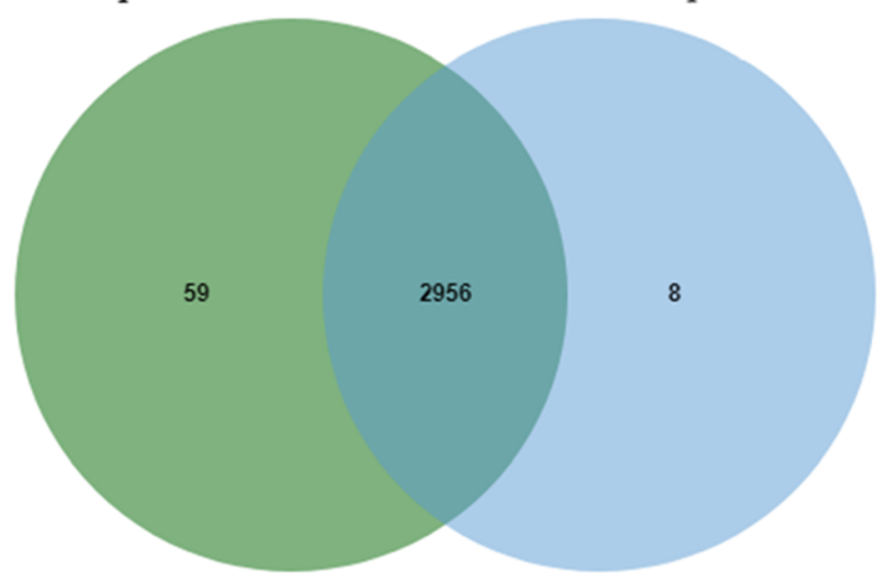

(b)

(c)

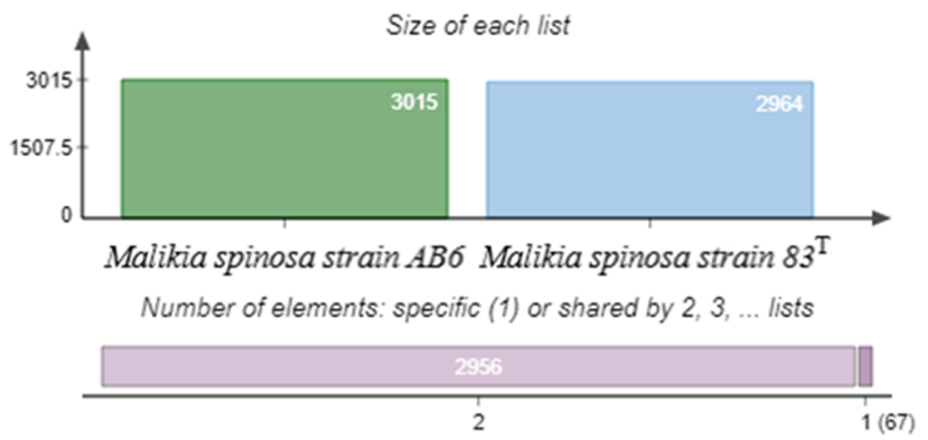

and $\mathrm{K} 601^{\mathrm{T}}$ (Oosterkamp et al. 2013). Hydroxylation of the benzene ring catalysed by phenol monooxygenases is a well-described process (Pérez-Pantoja et al. 2010), and their role in toluene degradation is also well documented (Cafaro et al. 2004; Martínez-Lavanchy et al. 2015).

Although ethylbenzene dioxygenase coding gene was not found in the genome of strain AB6, it was able to degrade ethylbenzene. Beside the pathway using the aromatic ring oxidation of ethylbenzene, the ethyl group oxidation catalysed by naphthalene dioxygenase is also feasible (Lee and Gibson 1996; Lee et al. 2019). Screening of the genome sequence for dioxygenases revealed the presence of genes, encoding the small and large subunits of a naphthalene dioxygenase, and were part of a naphthalene degradation gene cluster (i.e. a nag operon). This operon encoded salicylate-5-hydroxylase and gentisate 1,2dioxygenase enzymes as well, which were reported earlier as the key naphthalene metabolic enzymes in the case of Polaromonas naphthalenivorans CJ2 and Ralstonia sp. U2 (Park et al. 2007; Pumphrey and Madsen 2007; Zhou et al. 2001). Thereby, it can be postulated that strain AB6 could degrade ethylbenzene due to the presence of the nag operon, and it probably has the ability to degrade naphthalene as well.

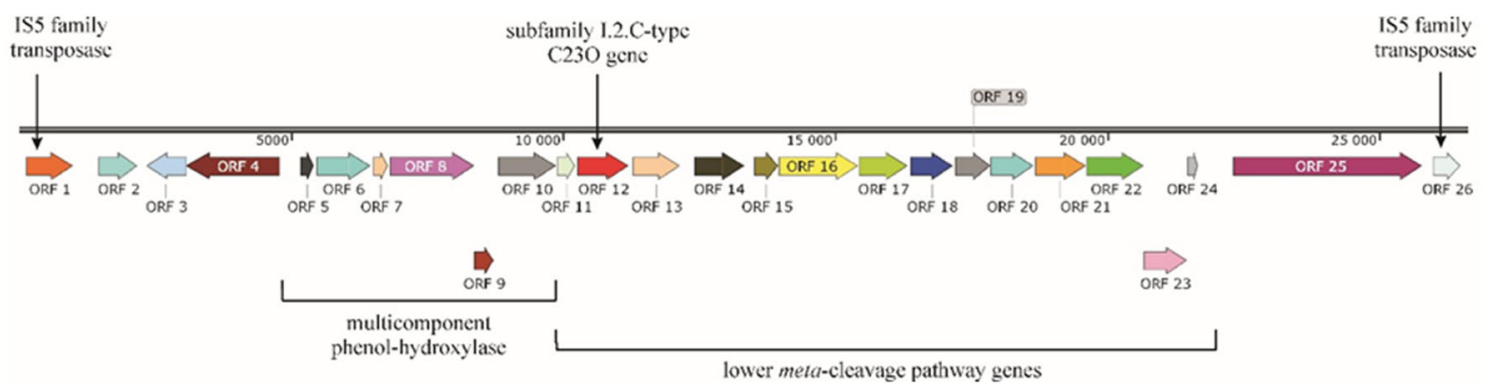

Fig. 7 Schematic representation of the phenol-degradation cluster in the genome of Malikia spinosa AB6. Arrows indicate the orientation of the ORFs. Table S1 of Online Resource 2 contains the detailed description of the ORFs 


\section{Concluding remarks}

Results of the present study shed light on the aromatic hydrocarbon-degrading ability of Malikia spinosa strains, thus providing evidence on our earlier presumption that this bacterium can act as a degrader in BTEX-contaminated environments, but mostly under strictly aerobic conditions (Táncsics et al. 2010; Benedek et al. 2018). This observation also revealed that bacteria, which encode subfamily I.2.C-type extradiol dioxygenase enzyme, will not be automatically able to degrade monoaromatic hydrocarbons under microaerobic conditions. Indeed, harbouring a subfamily I.2.C-type C23O gene is not the sole requirement of microaerobic aromatic hydrocarbon degradation, which was also shown by us earlier in the case of Zoogloea oleivorans strain Buc ${ }^{\mathrm{T}}$ (Táncsics et al. 2020). Moreover, based on the whole-genome analysis of Malikia spinosa strain AB6, it can be suggested that subfamily I.2.C-type $\mathrm{C} 23 \mathrm{O}$ genes easily spread among members of the Betaproteobacteriales through transposon-mediated HGT events.

Acknowledgements The authors are grateful for Károly Bóka (Department of Plant Anatomy, Eötvös Loránd University, Budapest, Hungary) for his essential help in the transmission electron microscopic observations

Funding information Open access funding provided by Szent István University (SZIE). This research was supported by the Thematic Excellence Program (NKFIH-831-10/2019) of Szent István University, awarded by the Ministry for Innovation and Technology of Hungary.

Open Access This article is licensed under a Creative Commons Attribution 4.0 International License, which permits use, sharing, adaptation, distribution and reproduction in any medium or format, as long as you give appropriate credit to the original author(s) and the source, provide a link to the Creative Commons licence, and indicate if changes were made. The images or other third party material in this article are included in the article's Creative Commons licence, unless indicated otherwise in a credit line to the material. If material is not included in the article's Creative Commons licence and your intended use is not permitted by statutory regulation or exceeds the permitted use, you will need to obtain permission directly from the copyright holder. To view a copy of this licence, visit http://creativecommons.org/licenses/by/4.0/.

\section{References}

Aburto A, Ball AS (2009) Bacterial population dynamics and separation of active degraders by stable isotope probing during benzene degradation in BTEX-impacted aquifer. Rev Int Contam Ambient 25: $147-156$

Aburto A, Fahy A, Coulon F, Lethbridge G, Timmis KN, Ball AS, McGenity TJ (2009) Mixed aerobic and anaerobic microbial communities in benzene-contaminated groundwater. J Appl Microbiol $106: 317-328$
Aburto A, Peimbert M (2011) Degradation of a benzene-toluene mixture by hydrocarbon-adapted bacterial communities. Ann Microbiol 61: 553-562

Aziz RK, Bartels D, Best AA, DeJongh M, Disz T, Edwards RA, Formsma K, Gerdes S, Glass EM, Kubal M, Meyer F, Olsen GJ, Olson R, Osterman AL, Overbeek RA, McNeil LK, Paarmann D, Paczian T, Parrello B, Pusch GD, Reich C, Stevens R, Vassieva O, Vonstein V, Wilke A, Zagnitko O (2008) The RAST Server: Rapid Annotations using Subsystems Technology. BMC Genomics 9:75

Benedek T, Szentgyörgyi F, Szabó I, Kriszt B, Révész F, Radó J, Maróti G, Táncsics A (2018) Aerobic and oxygen-limited enrichment of BTEX-degrading biofilm bacteria: dominance of Malikia versus Acidovorax species. Environ Sci Pollut Res Int 25:32178-32195

Benedek T, Táncsics A, Szabó I, Farkas M, Szoboszlay S, Fábián K, Maróti G, Kriszt B (2016) Polyphasic analysis of an AzoarcusLeptothrix-dominated bacterial biofilm developed on a stainless steel surface in a gasoline-contaminated hypoxic groundwater. Environ Sci Pollut Res Int 23:9019-9035

Borsodi AK, Aszalós JM, Bihari P, Nagy I, Schumann P, Spröer C, Kovács AL, Bóka K, Óvári M, Szili-Kovács T, Tóth E (2019) Anaerobacillus alkaliphilus sp. nov., a novel alkaliphilic and moderately halophilic bacterium. Int J Syst Evol Microbiol 69:631-637

Brettin T, Davis JJ, Disz T, Edwards RA, Gerdes S, Olsen GJ, Olson R, Overbeek R, Parrello B, Pusch GD, Shukla M, Thomason JA, Stevens R, Vonstein V, Wattam AR, Xia F (2015) RASTtk: A modular and extensible implementation of the RAST algorithm for building custom annotation pipelines and annotating batches of genomes. Sci Rep 5:8365

Cafaro V, Izzo V, Scognamiglio R, Notomista E, Capasso P, Casbarra A, Pucci P, di Donato A (2004) Phenol hydroxylase and toluene/oxylene monooxygenase from Pseudomonas stutzeri OX1: interplay between two enzymes. Appl Environ Microbiol 70:2211-2219

Edgar RC, Haas BJ, Clemente JC, Quince C, Knight R (2011) UCHIME improves sensitivity and speed of chimera detection. Bioinformatics 27:2194-2200

El-Naas MH, Acio JA, El Telib AE (2014) Aerobic biodegradation of BTEX: progresses and prospects. J Environ Chem Eng 2:1104 1122

Fahy A, Ball AS, Lethbridge G, Timmis KN, McGenity TJ (2008) Isolation of alkali-tolerant benzene-degrading bacteria from a contaminated aquifer. Lett Appl Microbiol 47:60-66

Fahy A, McGenity TJ, Timmis KN, Ball AS (2006) Heterogeneous aerobic benzene-degrading communities in oxygen-depleted groundwaters. FEMS Microbiol Ecol 58:260-270

Farkas M, Szoboszlay S, Benedek T, Révész F, Veres PG, Kriszt B, Táncsics A (2017) Enrichment of dissimilatory Fe(III)-reducing bacteria from groundwater of the Siklós BTEX-contaminated site (Hungary). Folia Microbiol 62:63-71

Fenga C, Gangemi S, Costa C (2016) Benzene exposure is associated with epigenetic changes (Review). Mol Med Rep 13:3401-3405

Hammer Ø, Harper DAT, Ryan PD (2001) PAST: Paleontological statistics software package for education and data analysis. Palaeontol Electron 4:9

Jechalke S, Franchini AG, Bastida F, Bombach P, Rosell M, Seifert J, von Bergen M, Vogt C, Richnow HH (2013) Analysis of structure, function, and activity of a benzene-degrading microbial community. FEMS Microbiol Ecol 85:14-26

Kaplan CW, Kitts CL (2004) Bacterial succession in a petroleum land treatment unit. Appl Environ Microbiol 70:1777-1786

Keller AH, Kleinsteuber S, Vogt C (2018) Anaerobic benzene mineralization by nitrate-reducing and sulfate-reducing microbial consortia enriched from the same site: comparison of community composition and degradation characteristics. Microb Ecol 75:941-953

Kim SJ, Park SJ, Jung MY, Kim JG, Madsen EL, Rhee SK (2014) An uncultivated nitrate-reducing member of the genus Herminiimonas degrades toluene. Appl Environ Microbiol 80:3233-3243 
Klindworth A, Pruesse E, Schweer T, Peplies J, Quast C, Horn M, Glöckner FO (2013) Evaluation of general 16S ribosomal RNA gene PCR primers for classical and next-generation sequencingbased diversity studies. Nucleic Acids Res 41:e1

Kozich JJ, Westcott SL, Baxter NT, Highlander SK, Schloss PD (2013) Development of a dual-index sequencing strategy and curation pipeline for analyzing amplicon sequence data on the MiSeq Illumina sequencing platform. Appl Environ Microbiol 79:5112-5120

Kukor JJ, Olsen RH (1996) Catechol 2,3-dioxygenases functional in oxygen-limited (hypoxic) environments. Appl Environ Microbiol 62: $1728-1740$

Kumar S, Stetcher G, Tamura K (2016) MEGA7: Molecular evolutionary genetics analysis version 7.0 for bigger datasets. Mol Biol Evol 33: $1870-1874$

Kunin V, Engelbrektson A, Ochman H, Hugenholtz P (2010) Wrinkles in the rare biosphere: pyrosequencing errors can lead to artificial inflation of diversity estimates. Environ Microbiol 12:118-123

Lee K, Gibson DT (1996) Toluene and ethylbenzene oxidation by purified naphthalene dioxygenase from Pseudomonas sp. strain NCIB 9816-4. Appl Environ Microbiol 62:3101-3106

Lee I, Kim YO, Park SC, Chun J (2016) OrthoANI: An improved algorithm and software for calculating average nucleotide identity. Int J Syst Evol Microbiol 66:1100-1103

Lee Y, Lee Y, Jeon CO (2019) Biodegradation of naphthalene, BTEX, and aliphatic hydrocarbons by Paraburkholderia aromaticivorans BN5 isolated from petroleum-contaminated soil. Sci Rep 9:860

Leifson E (1962) Pseudomonas spinosa n. sp. Int Bull Bacteriol Nomencl Taxon 12:89-92

Leuthner B, Leutwein C, Schulz H, Hörth P, Haehnel W, Schiltz E, Schägger H, Heider J (1998) Biochemical and genetic characterization of benzylsuccinate synthase from Thauera aromatica: a new glycyl radical enzyme catalysing the first step in anaerobic toluene metabolism. Mol Microbiol 28:615-628

Martínez-Lavanchy PM, Chen Z, Lünsmann V, Marin-Cevada V, Vilches-Vargas R, Pieper DH, Reiche N, Kappelmeyer U, Imparato V, Junca H, Nijenhuis I, Müller JA, Kuschk P, Heipieper HJ (2015) Microbial toluene removal in hypoxic model constructed wetlands occurs predominantly via the ring monooxygentation pathway. Appl Environ Microbiol 81:6241-6252

Meier-Kolthoff JP, Auch AF, Klenk HP, Göker M (2013) Genome sequence-based species delimitation with confidence intervals and improved distance functions. BMC Bioinformatics 14:60

Ohad I, Danon D, Hestrin S (1963) The use of shadow-casting technique for measurement of the width of elongated particles. J Cell Biol 17: $321-326$

Oosterkamp MJ, Veuskens T, Saia FT et al (2013) Genome analysis and physiological comparison of Alicycliphilus denitrificans strains BC and $\mathrm{K} 601^{\mathrm{T}}$. PLoS One 8:e66971

Overbeek R, Olson R, Pusch GD, Olsen GJ, Davis JJ, Disz T, Edwards RA, Gerdes S, Parrello B, Shukla M, Vonstein V, Wattam AR, Xia F, Stevens R (2014) The SEED and the Rapid Annotation of microbial genomes using Subsystems Technology (RAST). Nucleic Acids Res 42:D206-D2014

Park M, Jeon Y, Jang HH, Ro HS, Park W, Madsen EL, Jeon CO (2007) Molecular and biochemical characterization of 3-hydroxybenzoate 6-hydroxylase from Polaromonas naphthalenivorans CJ2. App1 Environ Microbiol 73:5146-5152

Pérez-Pantoja D, González B, Pieper DH (2010) Aerobic degradation of aromatic hydrocarbons. In: Timmis KN, editor. Handbook of hydrocarbon and lipid microbiology. Berlin, Germany: Springer-Verlag Berlin Heidelberg. pp. 799-837.
Prince RC, Amande TJ, McGenity TJ (2018) Prokaryotic hydrocarbon degraders. In: McGenity T (ed) Taxonomy, genomics and ecophysiology of hydrocarbon-degrading microbes. Handbook of hydrocarbon and lipid microbiology. Springer, Berlin, Heidelberg, pp 1669 1692

Pumphrey GM, Madsen EL (2007) Naphthalene metabolism and growth inhibition by naphthalene in Polaromonas naphthalenivorans strain CJ2. Microbiology 153:3730-3738

Quast C, Pruesse E, Yilmaz P, Gerken J, Schweer T, Yarza P, Peplies J, Glöckner FO (2013) The SILVA ribosomal RNA gene database project: improved data processing and web-based tools. Nucleic Acids Res 41:D590-D596

Révész F, Figueroa-Gonzalez PA, Probst AJ, Kriszt B, Banerjee S, Szoboszlay S, Maróti G, Táncsics A (2020) Microaerobic condiions caused the overwhelming dominance of Acinetobacter spp. and the marginalization of Rhodococcus spp. in diesel fuel/crude oil mixture-amended enrichment cultures. Arch Microbiol 202:329 342

Schloss PD, Westcott SL, Ryabin T, Hall JR, Hartmann M, Hollister EB, Lesniewski RA, Oakley BB, Parks DH, Robinson CJ, Sahl JW, Stres B, Thallinger GG, Van Horn DJ, Weber CF (2009) Introducing mothur: open-source platform-independent community-supported software for describing and comparing microbial communities. Appl Environ Microbiol 75:7537-7541

Singleton DR, Lee J, Dickey AN, Stroud A, Scholl EH, Wright FA, Aitken MD (2018) Polyphasic characterization of four soil-derived phenanthrene-degrading Acidovorax strains and proposal of Acidovorax carolinensis sp. nov. Syst Appl Microbiol 41:460-472

Sperfeld M, Diekert G, Studenik S (2018) Anaerobic aromatic compound degradation in Sulfuritalea hydrogenivorans sk43H. FEMS Microbiol Ecol 95:fiy199

Spring S, Wagner M, Schumann P, Kampfer P (2005) Malikia granosa gen. nov., sp. nov., a novel polyhydroxyalkanoate- and polyphosphate-accumulating bacterium isolated from activated sludge, and reclassification of Pseudomonas spinosa as Malikia spinosa comb. nov. Int J Syst Evol Microbiol 55:621-629

Szoboszlay S, Atzél B, Kukolya J, Tóth EM, Márialigeti K, Schumann P, Kriszt B (2008) Chryseobacterium hungaricum sp. nov., isolated from hydrocarbon-contaminated soil. Int J Syst Evol Microbiol 58: $2748-2754$

Táncsics A, Farkas M, Horváth B, Maróti G, Bradford LM, Lueders T, Kriszt B (2020) Genome analysis provides insights into microaerobic toluene-degradation pathway of Zoogloea oleivorans Buc $^{\mathrm{T}}$. Arch Microbiol 202:421-426

Táncsics A, Farkas M, Szoboszlay S, Szabó I, Kukolya J, Vajna B, Kovács B, Benedek T, Kriszt B (2013) One-year monitoring of meta-cleavage dioxygenase gene expression and microbial community dynamics reveals the relevance of subfamily I.2.C. extradiol dioxygenases in hypoxic, BTEX-contaminated groundwater. Syst Appl Microbiol 36:339-350

Táncsics A, Szabó I, Baka E, Szoboszlay S, Kukolya J, Kriszt B, Márialigeti K (2010) Investigation of catechol 2,3-dioxygenase and 16S rRNA gene diversity in hypoxic, petroleum hydrocarbon contaminated groundwater. Syst Appl Microbiol 33:398-406

Táncsics A, Szoboszlay S, Szabó I, Farkas M, Kovács B, Kukolya J, Mayer Z, Kriszt B (2012) Quantification of subfamily I.2.C catechol 2,3-dioxygenase mRNA transcripts in groundwater samples of an oxygen-limited BTEX-contaminated site. Environ Sci Technol 46: 232-240

Tatusova T, DiCuccio M, Badretdin A, Chetvernin V, Nawrocki EP, Zaslavsky L, Lomsadze A, Pruitt KD, Borodovsky M, Ostell J 
(2016) NCBI prokaryotic genome annotation pipeline. Nucleic Acids Res 44:6614-6624

Tindall BJ, Rosselló-Móra R, Busse HJ, Ludwig W, Kämpfer P (2010) Notes on the characterization of prokaryote strains for taxonomic purposes. Int J Syst Evol Microbiol 60:249-266

Tribelli PM, Rossi L, Ricardi MM, Gomez-Lozano M, Molin S, Raiger Iustman LJ, Lopez NI (2018) Microaerophilic alkane degradation in Pseudomonas extremaustralis: a transcriptomic and physiological approach. J Ind Microbiol Biotechnol 45:15-23

Xu L, Dong Z, Fang L, Luo Y, Wei Z, Guo H, Zhang G, Gu YQ, Colemann-Derr D, Xia Q, Wang Y (2019) OrthoVenn2: a web server for whole-genome comparison and annotation of orthologous clusters across multiple species. Nucleic Acids Res 47:W52-W58

Zhou NY, Fuenmayor SL, Williams PA (2001) nag genes of Ralstonia (formerly Pseudomonas) sp. strain U2 encoding enzymes for gentisate catabolism. J Bacteriol 183:700-708

Publisher's note Springer Nature remains neutral with regard to jurisdictional claims in published maps and institutional affiliations. 